\title{
EFEITO DE ENZIMAS AMILOLÍTICAS DE Aspergillus Awamori SOBRE A DIGESTÃO DO AMIDO EM BOVINOS
}

\author{
Patrícia Rabelo De Freitas ${ }^{1}$, Cirano José De Ulhôa², Reginaldo Ferreira Nassar², Cristielle Nunes Souto ${ }^{3^{*}}$, \\ Vinicius Santana Mota ${ }^{1}$, Delma Machado Cantisani Padua ${ }^{1}$
}

\author{
1Pontifícia Universidade Católica de Goiás, Av. Engler, 507 - Jardim Marlisa, Goiânia - GO, 74885-460 \\ 2Universidade Federal de Goiás (UFG), Instituto de Ciências Biológicas, - Alameda Palmeiras, S/n - Chácaras Califórnia, Goiânia - GO, \\ 74710-310 \\ 3Universidade Federal de Goiás (UFG), Escola de Veterinária e Zootecnia, Rodovia Goiânia, km 8, s/n - Campus Samambaia, Goiânia - \\ GO, 74001-970
}

Autor para correspondência: Cristielle Nunes Souto, cristielle_nunes@hotmail.com

RESUMO: Avaliou-se o efeito de uma solução de amilase produzida por Aspergillus awamori sobre a digestibilidade in vitro da matéria seca (DIVMS) de milho. Foram realizados dois experimentos, onde o primeiro a solução de enzima amilase foi aplicada por pulverização em $24 \mathrm{~g}$ de milho moído $(2 \mathrm{~mm})$ e o segundo a solução de enzima amilase foi aplicado no fluido ruminal. Os tratamentos foram: controle ( $0 \mathrm{~mL}$ de enzima), $5 \mathrm{~mL}$ ( $5 \mathrm{~mL}$ de enzima) e $10 \mathrm{~mL}$ (10 mL de enzima) para cada experimento. Para a coleta de líquido ruminal foi utilizado um bovino de peso aproximado de $380 \mathrm{~kg}$ e o ensaio da DIVMS foi obtido usando a técnica de rúmen artificial adaptada. Para os dois experimentos foi adotado o delineamento inteiramente casualizado, em esquema de parcelas subdivididas $3 \times 6$, com quatro repetições (jarros). As parcelas foram constituídas por milho tratado com três diferentes níveis de enzima e as subparcelas por seis momentos de digestão. Para enzima amilase aplicada no líquido ruminal o resultado de DIVMS para os três tratamentos nos períodos de 3, 6 e 12 horas não diferiram estatisticamente entre si. Entre 0 tratamento controle e $5 \mathrm{~mL}$ houve diferença significativa nos tempos 15 'e 1,5 horas. Foi observado maior DIVMS para o tratamento controle, em relação aos $5 \mathrm{~mL}$, com valores de $54,54 \%$ e 49,05, e não houve diferença nos tempos $3,6,12$ e 24 horas $(P>0,05)$. Entre o tratamento controle e o tratamento com $10 \mathrm{~mL}$ de enzima não houve diferença no tempo 15' e 24 horas. A DIVMS do controle foi superior a tratamento $10 \mathrm{~mL}(28,74 \%$ e 10,53\% respectivamente). A DIVMS foi superior para o tratamento controle, indicando que os níveis de 5 e $10 \mathrm{~mL}$ de enzimas injetados no fluido ruminal não aumentaram a DIVMS $(P>0,05)$. Para amilase aplicada por pulverização em $24 \mathrm{~g}$ de milho moído, no tempo de 15', observou-se que o tratamento controle e $5 \mathrm{~mL}$ não diferiram estastiticamente $(P>0,05)$. No entanto, $010 \mathrm{~mL}$ de enzima melhorou a DIVMS em 55,54\%, quando comparado ao grupo controle. Foi possível concluir que o tratamento com $5 \mathrm{~mL}$ de enzima aumentou a DIVMS em tempos de 3 e 24 horas de incubação e com a aplicação de $10 \mathrm{~mL}$ de enzima a DIVMS aumentou em todos os tempos de incubação.

PALAVRAS-CHAVE: ANKOM, amilase, degradabilidade, fungo, rúmen.

\section{EFFECT OF AMYLOLITICS ENZYMES OF THE Aspergillus awamori ON STARCH DIGESTION IN CATTLE}

ABSTRACT: We evaluated the effect of a solution of amylase produced by Aspergillus awamori on the in vitro dry matter (DIMS) of corn. Two experiments were conducted, where the first solution of the enzyme amylase was applied by spraying $24 \mathrm{~g}$ ground corn $(2 \mathrm{~mm})$ and the second amylase enzyme solution was applied in rumen fluid. He treatments were: control ( 0 enzyme), ( $5 \mathrm{ml}$ of enzyme) and T2 (10 $\mathrm{ml}$ of enzyme) for each experiment. The test DIVMS was obtained using the technique of artificial rumens adapted during periods of 15 ', 1.5, 3, 6, 12 and 24 hours. For the collection of rumen fluid was used for cattle weighing approximately $380 \mathrm{~kg}$. For both experiments was adopted a completely randomized design, with treatments consisting of corn treated with three different enzyme levels and repeated measures conducted in six times the digestion (15 ', 1.5, $3,6,12$ and 24 hours), with four replicates per treatment. For amylase enzyme applied to the result of ruminal DIVMS for the three treatments at 3, 6 and 12 hours did not differ statistically. Between treatment and control was 
no significant difference in T1 times 15 'and 1.30' hours. DIVMS was higher for the control treatment, with respect to T1, values of 54.54 and $49.05 \%$, and no difference in days 3, 6, 12 and 24 hours. Between treatment and control T2 there was no difference in time 15 "and 24 hours. The control was higher than $\mathrm{T} 228.74 \%$ and $10.53 \%$ respectively. DIVMS was superior to the control treatment, indicating that levels of 5 and $10 \mathrm{ml}$ of enzyme injected into the ruminal fluid increased in vitro data. For amylase applied by spraying $24 \mathrm{~g}$ of corn in time 15 ', it was observed that the treatment did not differ from control and T1. However, the T2 improved IVDMD of $55.54 \%$ compared to the control group. Treatment 1 DIVMS increased only in times of 3 and 24 hours of incubation, as compared to control. With the application of $10 \mathrm{ml}$ of enzyme, in vitro data increased in all incubation times in comparison with the control.

KEY WORDS: ANKOM, amylase, degradability, fungi, rumen

\section{INTRODUÇÃO}

Atualmente uma das maiores preocupações da humanidade é o aumento da produção de alimentos para atender a demanda crescente da população sem degradar o meio ambiente. É necessário criar novas tecnologias para aumentar a produção de maneira sustentável. Uma das inovações é a biotecnologia enzimática, a qual utiliza enzima na alimentação animal para melhor aproveitamento do alimento e para aumentar a produtividade. A enzimologia industrial é um importante ramo da biotecnologia, pois permite às indústrias usarem processos mais econômicos, diminuindo o consumo de energia, sendo mais confiáveis com menor agressão ao meio ambiente (Kebreab et al., 2010).

As enzimas atuam na remoção dos fatores antinutricionais, tornando certos nutrientes disponíveis para a absorção e também aumentando 0 valor energético de ingredientes mais baratos. As enzimas estão sendo cada vez mais aplicadas em diferentes setores industriais, devendo-se, principalmente, a vantagens operacionais como especificidade de reação e alta eficiência de conversão. As principais metas de suplementação enzimática para os animais são: remover ou destruir fatores antinutricionais dos grãos; aumentar a digestibilidade total da ração; potencializar a ação das enzimas endógenas e diminuir a poluição ambiental causada por nutrientes excretados nas fezes (Passini et al., 2003). As amilases são hidrolases capazes de degradar 0 amido e seus produtos de hidrólise, até sacarídeos menores. São amplamente distribuídas na natureza, encontradas na indústria devida á grande aplicação do amido e de seus derivados em processos industriais. Pesquisas na área de suplementos enzimáticos para dietas de ruminantes têm sido realizadas principalmente com celulases e hemicelulases enquanto as atividades envolvidas no processo de digestão do amido têm sido pouco estudadas (Kameda et al., 2007; Tricarico et al., 2008).

Uma vez que 0 amido representa 0 maior componente nas dietas de bovinos de alta produtividade, a utilização de suplementos enzimáticos para manipular a digestão do amido no rúmen pode permitir melhora na produtividade. A utilização de uma enzima pode propiciar aumento de produtividade com menor capital investido.

0 objetivo do presente trabalho foi avaliar 0 efeito de amilase obtida de Aspergillus awamori sobre a digestibilidade In vitro da matéria seca (DIVMS) do milho para bovinos em regime de confinamento.

\section{MATERIAL E MÉTODOS}

Os experimentos de produção, caracterização enzimática, incubação e de DIVMS foram conduzidos no Laboratório de Enzimologia e no de Fisiologia da Digestão do Instituto de Ciências Biológicas II (ICB II), da Universidade Federal de Goiás (UFG), Campus Samambaia, localizado no município de Goiânia - Goiás.

\section{Linhagem utilizada e manutenção do fungo}

A amostra do fungo utilizada foi de Aspergillus awamori isolada do solo na Universidade de Brasília. $O$ fungo foi cultivado em meio MEX [extrato de malte $3,0 \%$ (p/v) e Ágar 2,0\% (p/v)], autoclavado a $120^{\circ} \mathrm{C}$ por 20 minutos. A cultura foi mantida por 4 dias a $30^{\circ} \mathrm{C}$ em estufa de ventilação forçada e, posteriormente, as placas foram estocadas a $4{ }^{\circ} \mathrm{C}$ para utilização.

\section{Produção, inoculação, filtragem e liofilização da solução enzimática}

Três discos de cultura $(5 \mathrm{~mm})$, contendo esporos do fungo Aspergillus awamori foram 
inoculados em erlenmeyers de 1,0 L, contendo 250 $\mathrm{mL}$ de meio de indução (extrato de levedura, $1,0 \mathrm{~g}$; MgSO4, 0,05 g; FeSO4; 0,01g; CaCl2 2H2O, 0,01 g; KH2PO4, 0,02 g; (NH4)2SO4, 0,125 g; Amido, 1\%; Água destilada q.s.p. $100 \mathrm{~mL}$ ). Os erlenmeyers foram incubados em agitador rotatório (Controlled Environment Incubator Shacker, Brunswick Scientific Co. Inc., U.S.A) a $30^{\circ} \mathrm{C}$ e velocidade de $180 \mathrm{rpm}$. Após 48 horas de cultivo, a solução enzimática foi filtrada a vácuo. Alíquotas foram retiradas e congeladas para a avaliação da atividade de amilase e posterior utilização.

A solução contendo a enzima amilase foi submetida à filtragem á vácuo por filtros de papel, concentrada pelo processo de liofilização e ressuspendida (retorno ao estado líquido) para utilização. A solução enzimática foi mantida em geladeira a temperatura de 4 a $8^{\circ} \mathrm{C}$ para utilização.

\section{Determinação da atividade de amilase}

A atividade amilolítica foi determinada pelo método sacarificante que se baseia na produção de açúcares redutores (Miller, 1959). A atividade enzimática encontrada foi de $46,54 \mathrm{U} \mathrm{mL}^{-1}$. A $40 \mu \mathrm{l}$ de tampão citrato-fosfato (50 mmol. L-1, $\mathrm{pH} \mathrm{6,8),} \mathrm{foram}$ adicionados $60 \mu \mathrm{l}$ de amostra enzimática e $100 \mu \mathrm{l}$ de solução de amido (0,5\%). A mistura foi incubada a 39 ${ }^{\circ} \mathrm{C}$ por 15 minutos. Posteriormente, $1,0 \mathrm{~mL}$ de reagente ácido dinitrosalicílico\{ (10 g..-1) (DNS), $100 \mathrm{~mL}$ de $\mathrm{NaOH}\left(2 \mathrm{mmol} . \mathrm{L}^{-1}\right), 300 \mathrm{~g} . \mathrm{L}^{-1}$ de tartarato de sódio e potássio\} foi adicionado aos tubos de ensaio. $\mathrm{A}$ mistura foi fervida por 5 minutos em banho-maria a $96^{\circ} \mathrm{C}$ e a absorbância determinada a $550 \mathrm{~nm}$. A quantidade de açucares redutores formados é calculada de acordo com uma curva padrão de glicose (Miller, 1959). Uma unidade (U) de atividade sacarificante foi definida como a quantidade de enzima que libera 0,1 mg de açúcar redutor por minuto de reação.

\section{Delineamento Experimental}

Foram testados dois métodos de adição da enzima amilolítica com a finalidade de determinar a melhor forma de utilização e efeito, nos dois experimentos. Na primeira forma a enzima amilase foi aspergida sobre o substrato (milho moído) e a segunda forma a enzima amilase foi aplicada diretamente no líquido ruminal. No primeiro método a aspersão ocorreu em $24 \mathrm{~g}$ de substrato, acondicionados em sacos de náilon. Os sacos de náilon contendo substrato tratado foram colocados dentro dos jarros da incubadora no momento da incubação. No segundo método a amilase foi aplicada diretamente nos jarros, no momento da incubação, contendo líquido ruminal, solução tampão e sacos de náilon com substrato.

Foi adotado 0 delineamento inteiramente casualizado, em esquema de parcelas subdivididas 3 $x 6$, com quatro repetições (jarros). As parcelas foram constituídas por milho tratado com três diferentes níveis de enzima e as subparcelas por seis períodos de digestão do milho tratado.

\section{Preparação das soluções tampões}

Primeiramente foi misturado $266 \mathrm{~mL}$ da solução $B$ (15 g de $\mathrm{Na}_{2} \mathrm{CO}_{3}$ e $1 \mathrm{~g}$ de $\mathrm{Na}_{2} \mathrm{~S}_{9} \mathrm{H}_{2} \mathrm{O}$, para $1 \mathrm{~L}$ de água destilada) em $1330 \mathrm{~mL}$ da solução $\mathrm{A}$ (10 g de $\mathrm{KH}_{2} \mathrm{PO}_{4} ; 0,5 \mathrm{~g}$ de $\mathrm{MgSO}_{4} 7 \mathrm{H}_{2} \mathrm{O} ; 0,5 \mathrm{~g}$ de $\mathrm{NaCl} ; 0,1 \mathrm{~g}$ de $\mathrm{CaCl}_{2} 2 \mathrm{H}_{2} \mathrm{O}$ e $0,5 \mathrm{~g}$ de uréia, em $1 \mathrm{~L}$ de água destilada). A quantidade exata de $\mathrm{A}$ para $\mathrm{B}$ (relação 1:5) deve ser ajustada para obtenção do pH final 6,8 a $39^{\circ} \mathrm{C}$. Nenhum ajuste adicional de $\mathrm{pH}$ é necessário. A quantidade aproximada de $1600 \mathrm{~mL}$ da solução tampão foi adicionada por jarro, colocados na incubadora aproximadamente 4 horas antes da incubação para obtenção da temperatura de $39^{\circ} \mathrm{C}$.

\section{Preparação dos sacos de náilon}

Os sacos de filtro-náilon (F57 ANKOM®) foram identificados numericamente (48 amostras e 1 branco), mergulhados em acetona por 3 a 5 minutos, escoados e colocados em estufa com circulação forçada de ar a $55^{\circ} \mathrm{C}$ por dois minutos e posteriormente em estufa a $105^{\circ} \mathrm{C}$ durante $24 \mathrm{hs}$. A lavagem dos sacos em acetona foi executada para a remoção da solução surfactante que inibe a digestão microbiana. Após 40 minutos no dessecador, os sacos foram submetidos à pesagem (peso do saco de náilon vazio $=\mathrm{W} 1$ ).

Amostras de $0,5 \mathrm{~g}$ do milho tratado ou não por solução enzimática foram acondicionadas em sacos de filtro-náilon (F57 ANKOM®), e em seguida selados (peso do saco com amostra de milho =W2). Os sacos contendo o substrato (milho) foram reservados para 0 momento da incubação in vitro. 


\section{Coleta do líquido ruminal e incubação}

Para a coleta do líquido ruminal foi utilizado um bovino Nelore com peso aproximado de 380 $\mathrm{kg}$ provido de cânula no rúmen, mantido em baia individual, adaptado a dieta por período de 10 dias. A dieta, fornecida à vontade, após a coleta do líquido ruminal, consistiu de feno de Tifton com 7\% de proteína bruta (PB) e $1 \mathrm{~kg}$ de milho. Para cada tratamento no momento da incubação coletou-se 2000 $\mathrm{mL}$ de líquido ruminal, enviado ao laboratório por meio de garrafa térmica. 0 material foi homogeneizado à velocidade alta por 30 segundos, sendo em seguida filtrado e adicionados em jarros de vidro de $500 \mathrm{~mL}$, contendo solução tampão a $39^{\circ} \mathrm{C}$. Todo o processo ocorreu com a infusão de $\mathrm{CO}_{2}$. Os materiais utilizados para o manuseio do líquido ruminal foram aquecidos a temperatura de $39^{\circ} \mathrm{C}$. A mistura do líquido em liquidificador tem o objetivo de desalojar as bactérias da massa ruminal, assegurando a população microbiana para a fermentação in vitro.

Posteriormente, os sacos de filtro náilon foram introduzidos nos jarros (4 no total) da incubadora (TE150 TECNAL), contendo $400 \mathrm{~mL}$ de líquido ruminal e $1600 \mathrm{~mL}$ de solução tampão a $39^{\circ} \mathrm{C}$. Em meio anaeróbio foram incubados 48 sacos contendo amostra e um saco em branco (C1) para cada tratamento, sendo: jarro 1 sacos de número 1 a 12; jarro 2 sacos de número 13 a 24; jarro 3 sacos de número 25 a 36 e jarro 4 do 37 ao 48 e amostra em branco.

As amostras foram incubadas por 15; 1,5; 3; 6; 12 e 24 hs, para cada tratamento. Para cada horário de incubação foram retiradas 2 amostras, aleatoriamente de cada jarro (8 amostras no total), sempre com infusão de $\mathrm{CO}_{2}$ registrando o horário de retirada. Em seguida os sacos foram lavados por três vezes em água destilada e uma vez em acetona, escoados e acondicionadas em estufa de ventilação forçada a $105^{\circ} \mathrm{C}$ por $24 \mathrm{hs}$. Posteriormente as amostras foram retiradas da estufa, mantidas em dessecador por 40 minutos, pesadas e registradas para cálculo da DIVMS (W $\square)$.

\section{Digestibilidade in vitro da matéria seca (DIVMS)}

No ensaio de digestibilidade in vitro foi utilizada a metodologia descrita por (Tilley e Terry 1963) modificada para o fermentador ruminal (DAISY), seguindo a metodologia apresentada no manual de utilização do equipamento (ANKOM® Technology), fornecida pelo fabricante.

Para calcular a DIVMS utilizou-se a seguinte fórmula:

\% DIVMS $=100-(\mathrm{W} \square-(\mathrm{W} \square \times \mathrm{C} \square)) \times 100$

$(\mathrm{W} \square \mathrm{x} \mathrm{MS})$

Em que: $W \square=$ Peso saco vazio; $W \square=$ Peso da amostra; $\mathrm{W} \square=$ Peso final após DIVMS; $\mathrm{C} \square=$ Peso do saco em branco; MS = Matéria Seca.

\section{Determinação de glicose e matéria seca}

No momento da incubação foi retirada uma alíquota de líquido ruminal de cada jarro, por horário (15; 1,$5 ; 3 ; 6 ; 12$ e 24hs), para cada tratamento e armazenadas em freezer para determinação de glicose.

Para determinação da glicose foi utilizado à metodologia do Kit comercial de Glicose Enzimática Líquida Doles. Os valores de glicose foram registrados e lançados em planilha.

O ensaio para determinação de matéria seca foi realizado para cada tratamento (controle, $5 \mathrm{~mL}$ e 10 $\mathrm{mL}$ ). 0 cadinho foi mantido em estufa por 2 horas a $105^{\circ} \mathrm{C}$ para secagem, após 40 minutos em dessecador registrou-se o peso, em seguida foi adicionado $1,0 \mathrm{~g}$ da amostra (milho moído), mantendo em estufa a $105^{\circ} \mathrm{C}$ durante $24 \mathrm{hs}$ e determinado o peso final. 0 ensaio foi realizado em duplicata.

\section{Análise Estatística}

Os dados dos experimentos com o efeito da enzima amilase no substrato e da enzima adicionada diretamente no líquido ruminal foram submetidos à análise de variância e as médias comparadas pelo teste de Tukey a $5 \%$ de probabilidade. As análises estatísticas foram realizadas com auxílio do software R.

\section{RESULTADOS E DISCUSSÃO}

\section{Resultados de Matéria seca}

Para cada tratamento foi realizado o ensaio de determinação de matéria seca. Foram encontrados os valores descritos na tabela 1 , os quais foram utilizados na fórmula para determinar a DIVMS.

Resultados de DIVMS 
Tabela 1. Média dos valores de matéria seca para os diferentes níveis de enzima

\begin{tabular}{lcc}
\hline \multirow{2}{*}{ Níveis de enzima } & \multicolumn{2}{c}{ MATERIA SECA } \\
\cline { 2 - 3 } & Enzima aspergida no substrato & Enzima adicionada ao líquido ruminal \\
\hline Controle $(0 \mathrm{~mL})$ & 52,80 & 53,02 \\
$5 \mathrm{ML}(5 \mathrm{~mL})$ & 52,84 & 52,91 \\
$10 \mathrm{ML}(10 \mathrm{~mL})$ & 52,93 & 53,01 \\
\hline
\end{tabular}

\section{Aspersão da amilase sobre o substrato}

Verificou-se que no tempo inicial de 15 minutos, os tratamentos controle e $5 \mathrm{~mL}$ não diferiram entre si. Na tabela 1 com aplicação de $10 \mathrm{~mL}$ em 15 minutos foi observada melhora de $55,54 \%$ da digestibilidade, em relação ao controle. Esse resultado demonstra que 0 nível de $10 \mathrm{~mL}$ de enzima promoveu a hidrólise do amido antes da sua incubação no rúmen. Isso provavelmente ocorre pela especificidade da enzima amilase ter como seu substrato o amido. Harger (1982) afirma que as enzimas são denominadas de acordo com o substrato sobre o qual atuam, portanto, o termo amilase indica a ação sobre 0 amido.

Quando se comparou os tratamentos controle e $5 \mathrm{~mL}$, nos tempos de incubação 15 minutos, 1,5 horas, 6 horas e 12 horas observou-se que a DIVMS do milho não apresentou diferença significativa. Já para os tempos 3 hs foram de $23,58 \%$ e $28,08 \%$ e para $24 \mathrm{~h} 53,30 \%$ e $60,54 \%$ respectivamente, apresentando diferença significativa. Isso indica que a concentração de $5 \mathrm{~mL}$ de enzima melhorou a DIVMS para tempo de 3 e 24 horas.

Muito da variabilidade da atuação enzimática são atribuídas a fatores tais como o tipo e atividade da enzima, as condições de cultura empregada (Eun \& Beauchemin, 2007), nível de suplementação e enzima fornecida, estabilidade da enzima no aparelho digestivo (Yang et al., 2001; Giraldo et al., 2008), composição da dieta, método de aplicação da enzima e o balanço energético dos animais teste. Respostas positivas têm sido obtidas com adição de preparados enzimáticos à ração, mas quais as enzimas chave envolvidas e o mecanismo de ação ainda não são bem definidos (Beauchemin et al., 2003). Segundo o trabalho de Minafra (2007), pode-se observar que a enzima apresenta atividade alta na faixa de temperatura entre 30 a $70^{\circ} \mathrm{C}$, tendo 0 valor máximo de atividade enzimática na temperatura de $50{ }^{\circ} \mathrm{C}$, apresentando estabilidade nos pH fisiológicos 3,0 a 8,0.

Nas condições do presente trabalho, foi verificado que os valores do controle e $10 \mathrm{~mL}$ diferiram estatisticamente $(P<0,05)$, sendo que os resultados do tratamento $10 \mathrm{~mL}$ foram superiores aos do controle. Essa fato indica que 0 nível $10 \mathrm{~mL}$ de enzima melhorou a DIVMS para todos os tempos de incubação. Estudos revisados por (Medeiros e Lanna, 1999) mostram que o uso de enzimas exógenas na dieta de ruminantes pode proporcionar melhora na digestibilidade da ração. Segundo (Colombatto et al., 2007) há evidencias de uma combinação de efeitos pré e pós-alimentação, onde índice de aplicação da enzima e o tempo de interação de enzima-alimento, criam um complexo enzima-alimento estável, que protege as enzimas exógenas de proteólises no rúmen.

\section{Aplicação da amilase no líquido ruminal}

Com 15 minutos e 1,5 horas de incubação, foi observado maior DIVMS para o tratamento controle, em relação ao tratamento com $5 \mathrm{~mL}$ de enzima. $\mathrm{Na}$ tabela 2 verificou-se ainda que o tratamento controle proporcionou maior DIVMS, em relação ao $10 \mathrm{~mL}$ com aumentos de $28,74 \%$ e $10,53 \%$, para os tempos 15 ' e 24 horas, respectivamente. Verificou-se que a DIVMS foi maior para o tratamento controle, indicando que os níveis de $5 \mathrm{~mL}$ e $10 \mathrm{~mL}$ da enzima aplicados no líquido ruminal não aumentaram a DIVMS. Provavelmente, a falta de respostas à adição de 5 e 10 $\mathrm{mL}$ ocorreu pela inativação da enzima amilase devido a ação das proteases presentes no líquido ruminal. (Dukes 1993) relata que certas proteínas naturais, escapam da degradação ruminal, mas podem ser prontamente hidrolisadas pelas enzimas proteolíticas gastrointestinais. A proteólise bacteriana começa com a atividade extracelular da protease para produzir peptídios os quais são fagocitados e submetidos à hidrólise posterior dentro da célula bacteriana.

A enzima amilase, assim como outras enzimas utilizadas na alimentação de ruminantes deve resistir e conservar atividade considerável depois dos processos de fabricação e digestão. Os fatores que podem influenciar sua estabilidade, entre outros, são: a origem (microrganismo), o tipo de atividade, 
a composição da dieta, o modo de fazer a ração, 0 armazenamento, às condições durante 0 processo digestivo e a ação de enzimas endógenas (Francesch, 1996). Segundo (Borges, 1997) a estrutura molecar da enzima é bastante frágil e, consequentemente, podem ser desnaturados por calor, álcalis, metais pesados e outros agentes oxidantes.

Trabalho correlato como o de Colombatto et al. (2007) demonstra que quando enzimas foram adicionadas diretamente no líquido ruminal em vez de aplicadas ao alimento, nenhuma melhora foi observada.

\section{Resultados de Glicose}

\section{Aspersão da amilase no substrato}

Observaram-se maiores níveis de glicose no líquido ruminal para o tratamento controle e $5 \mathrm{~mL}$ no tempo inicial de 15 minutos em relação aos outros tempos de incubação. Na tabela 3 verificou-se que houve diferença significativa entre os tratamentos $5 \mathrm{~mL}$ e $10 \mathrm{~mL}$ com 15 minutos de incubação, sendo o $5 \mathrm{~mL}$ superior ao $10 \mathrm{~mL}$. Não houve diferença significativa entre o tratamento controle e $5 \mathrm{~mL}$ para os tempos de incubação 1,5; 3; 6 e 12 horas. No tratamento com 5
$\mathrm{mL}$ de enzima observou-se diferença significativa da atividade enzimática no tempo inicial sendo superior aos outros tempos de incubação.

\section{Aplicação de amilase no líquido ruminal}

Com a aplicação no líquido ruminal, não foi observado diferença significativa dos resultados de glicose para o tratamento controle, $5 \mathrm{~mL}$ e $10 \mathrm{~mL}$ nos tempos 15 '; 1,5; 3; 6 e 12 horas de incubação. Já para o tempo de 24 horas de incubação houve diferença significativo sendo o $10 \mathrm{~mL}$ superior aos demais tratamentos.

Diante dos resultados de glicose, tanto para enzima aspergida sobre o substrato como aplicada ao líquido ruminal, no tratamento com $10 \mathrm{~mL}$ de enzima observa-se que, com 24 horas de incubação, houve maior ação da atividade enzimática. (Gupta, 2003 e Pandey 2005) citam que as amilases hidrolisam moléculas de amido liberando diversos produtos, incluindo dextrinas e progressivamente pequenos polímeros compostos de unidades de glicose. A mesma ação foi verificada nos resultados de DIVMS demonstrados nas tabelas 1 e 2 .

Tabela 2. Média dos valores de DIVMS (\%) do milho moído submetido a diferentes níveis de enzima e os períodos de incubação

\begin{tabular}{ccccccc}
\hline \multirow{2}{*}{ Nível de enzimas $(\mathrm{mL})$} & \multicolumn{5}{c}{ Período de incubação ruminal (minutos e horas) } \\
\cline { 2 - 7 } & $15{ }^{\prime}$ & $1,5 \mathrm{~h}$ & $3 \mathrm{~h}$ & $6 \mathrm{~h}$ & $12 \mathrm{~h}$ & $24 \mathrm{~h}$ \\
\hline Controle $(0 \mathrm{~mL})$ & $22,82 \mathrm{bD}$ & $23,93 \mathrm{bD}$ & $23,57 \mathrm{cD}$ & $29,13 \mathrm{bC}$ & $38,06 \mathrm{bB}$ & $53,29 \mathrm{cA}$ \\
$5 \mathrm{ML}(5 \mathrm{~mL})$ & $23,60 \mathrm{bD}$ & $27,30 \mathrm{bCD}$ & $28,08 \mathrm{bCD}$ & $30,29 \mathrm{bC}$ & $41,83 \mathrm{bB}$ & $60,54 \mathrm{bA}$ \\
$10 \mathrm{ML}(10 \mathrm{~mL})$ & $35,50 \mathrm{aD}$ & $41,58 \mathrm{aC}$ & $38,50 \mathrm{aCD}$ & $39,81 \mathrm{aCD}$ & $60,60 \mathrm{aB}$ & $73,21 \mathrm{aA}$ \\
\hline
\end{tabular}

Médias seguidas pela mesma letra não diferem estatisticamente entre si pelo teste de Tukey a $5 \%$. Níveis de enzima - $\mathrm{CV} \%=7,28, \mathrm{GL} \%=2, \mathrm{QM} \%=1792,2544, \mathrm{~F} \%=228,9354$. Períodos de incubação: $\mathrm{CV} \%=5,99, \mathrm{GL} \%=5$, $\mathrm{QM} \%=2211,3350, \mathrm{~F} \%=417,8208$. Colunas, classificação com letras minúsculas; Linhas, classificação com letras maiúsculas.

Tabela 3. Média dos valores de DIVMS (\%) do líquido ruminal submetido a diferentes níveis de enzima e os períodos de incubação.

\begin{tabular}{lcccccc}
\hline \multirow{2}{*}{ Nível de enzimas $(\mathrm{mL})$} & \multicolumn{5}{c}{ Período de incubação ruminal (minutos e horas) } \\
\cline { 2 - 7 } & $15^{\prime}$ & $1,5 \mathrm{~h}$ & $3 \mathrm{~h}$ & $6 \mathrm{~h}$ & $12 \mathrm{~h}$ & $24 \mathrm{~h}$ \\
\hline Controle $(0 \mathrm{~mL})$ & $14,96 \mathrm{aC}$ & $14,24 \mathrm{aC}$ & $12,45 \mathrm{aC}$ & $24,06 \mathrm{aB}$ & $38,06 \mathrm{bB}$ & $48,06 \mathrm{aA}$ \\
$5 \mathrm{ML}(5 \mathrm{~mL})$ & $9,67 \mathrm{bC}$ & $9,55 \mathrm{bC}$ & $10,95 \mathrm{aC}$ & $11,42 \mathrm{aC}$ & $23,79 \mathrm{aB}$ & $50,40 \mathrm{aA}$ \\
$10 \mathrm{ML}(10 \mathrm{~mL})$ & $11,61 \mathrm{bC}$ & $13,46 \mathrm{aC}$ & $13,35 \mathrm{aC}$ & $14,13 \mathrm{aC}$ & $22,00 \mathrm{aB}$ & $43,59 \mathrm{bA}$ \\
\hline
\end{tabular}

Médias seguidas pela mesma letra não diferem estatisticamente entre si pelo teste de Tukey a $5 \%$. Níveis de enzima: $\mathrm{CV} \%=7,86, \mathrm{GL} \%=2, \mathrm{QM} \%=26,5161, \mathrm{~F} \%=10,6458$. Períodos de incubação: $\mathrm{CV} \%=7,84, \mathrm{GL} \%=5$, $\mathrm{QM} \%=2362.2851, \mathrm{~F} \%=951,7127$. Colunas, classificação com letras minúsculas; Linhas, classificação com letras maiúsculas. 
Tabela 4. Médias dos valores de glicose presente no líquido ruminal submetido a diferentes níveis de enzima e os períodos de incubação

\begin{tabular}{lcccccc}
\hline \multirow{2}{*}{ Nível de enzimas $(\mathrm{mL})$} & \multicolumn{7}{c}{ Período de incubação ruminal (minutos e horas) } \\
\cline { 2 - 7 } & $15^{\prime}$ & $1,5 \mathrm{~h}$ & $3 \mathrm{~h}$ & $6 \mathrm{~h}$ & $12 \mathrm{~h}$ & $24 \mathrm{~h}$ \\
\hline Controle $(0 \mathrm{~mL})$ & $16,84 \mathrm{bA}$ & $12,32 \mathrm{aA}$ & $5,13 \mathrm{aA}$ & $5,8 \mathrm{aA}$ & $3,19 \mathrm{bA}$ & $5,14 \mathrm{bA}$ \\
$5 \mathrm{ML}(5 \mathrm{~mL})$ & $74,91 \mathrm{aA}$ & $13,75 \mathrm{aB}$ & $3,28 \mathrm{aB}$ & $4,04 \mathrm{aB}$ & $2,63 \mathrm{bB}$ & $2,02 \mathrm{bB}$ \\
$10 \mathrm{ML}(10 \mathrm{~mL})$ & $5,91 \mathrm{bBC}$ & $5,11 \mathrm{aC}$ & $3,51 \mathrm{aC}$ & $9,16 \mathrm{aBC}$ & $30,15 \mathrm{aA}$ & $25,75 \mathrm{aAB}$ \\
\hline
\end{tabular}

Médias seguidas pela mesma letra não diferem estatisticamente entre si pelo teste de Tukey a $5 \%$. Níveis de enzima: $C V \%=81,46, G L \%=2, Q M \%=458,0591, F \%=4,2723$. Períodos de incubação: $C V \%=74,85, G L \%=5$, $\mathrm{QM} \%=1246,6830, \mathrm{~F} \%=13,7706$. Colunas, classificação com letras minúsculas; Linhas, classificação com letras maiúsculas.

Tabela 5. Média de glicose presente no líquido ruminal submetido a diferentes níveis de enzima e os períodos de incubação

\begin{tabular}{lcccccc}
\hline \multirow{2}{*}{ Nível de enzimas $(\mathrm{mL})$} & \multicolumn{6}{c}{ Período de incubação ruminal (minutos e horas) } \\
\cline { 2 - 7 } & $15^{\prime}$ & $1,5 \mathrm{~h}$ & $3 \mathrm{~h}$ & $6 \mathrm{~h}$ & $12 \mathrm{~h}$ & $24 \mathrm{~h}$ \\
\hline Controle $(0 \mathrm{~mL})$ & $4,09 \mathrm{aA}$ & $1,88 \mathrm{aA}$ & $2,68 \mathrm{aA}$ & $3,52 \mathrm{aA}$ & $2,13 \mathrm{aA}$ & $2,56 \mathrm{bA}$ \\
$5 \mathrm{ML}(5 \mathrm{~mL})$ & $4,01 \mathrm{aA}$ & $3,55 \mathrm{aA}$ & $1,53 \mathrm{aA}$ & $1,97 \mathrm{aA}$ & $2,71 \mathrm{aA}$ & $2,48 \mathrm{bA}$ \\
$10 \mathrm{ML}(10 \mathrm{~mL})$ & $191 \mathrm{aB}$ & $3,97 \mathrm{aB}$ & $5,74 \mathrm{aB}$ & $2,72 \mathrm{aB}$ & $5,41 \mathrm{aB}$ & $25,24 \mathrm{aA}$ \\
\hline
\end{tabular}

Médias seguidas pela mesma letra não diferem estatisticamente entre si pelo teste de Tukey a $5 \%$. Níveis de Enzima: CV\%=115,93, GL\%=2, QM\%=179,4706, $F \%=7,0789$. Período de incubação: $C V \%=92,25, G L \%=5$, $\mathrm{QM} \%=96,0982, \mathrm{~F} \%=5,9866$. Colunas, classificação com letras minúsculas; Linhas, classificação com letras maiúsculas.

Com essas informações entende-se que 0 aumento da DIVMS com nível de $10 \mathrm{~mL}$ de enzima com 24 horas de incubação deve-se a ação da enzima. (Colombatto et al., 2007) observaram valores de digestibilidade semelhante a este experimento sugerindo este efeito como a proteção enzimática sendo causada pela complexação do alimento com a enzima. Esta observação pode ser a mesma constatada no presente trabalho. Assim, conclui-se que a enzima amilase de Aspergillus awamori aumentou significativamente a DIVMS do amido na concentração de $10 \mathrm{~mL}$, nos tempos de 12 e 24 horas de incubação quando aplicada sobre o milho triturado. 0 complexo enzimático adicionado diretamente no líquido ruminal não alterou a DIVMS do amido.

\section{REFERÊNCIAS BIBLIOGRÁFICAS}

Beauchemin, K.A.; Colombatto D.; Morgavi, D.P.; Yang, W.Z. Use of exogenous fibrolytic enzymes to improve feed utilization by ruminants. Journal of Animal Science. 2003, 81, 37-47.
Borges, F.M.O. Utilização de enzimas em dietas avícolas. Caderno Técnico da Escola de Veterinária da UFMG, 1997, 20, 5-30.

Colombatto, D.; Moulda, F.L.; Bhatb, M.K. ; Owena, E. Influence of exogenous fibrolytic enzyme level and incubation $\mathrm{pH}$ on the in vitro ruminal fermentation of alfafa stems. Alimentação Animal Ciência e Tecnologia, 2007, 137, $150-162$.

Dukes, H.H.. Digestão no estômago dos ruminantes. In: Fisiologia dos animais domésticos. 11 ed. Guanabara Koogan, Rio de Janeiro, 1993, cap. 21.

Eun, J. S.; Beauchemin, K. A. Assessment of the efficacy of varying experimental exogenous fibrolytic enzymes using in vitro fermentation characteristics. Animal Feed Science and Technology. 2007, 132, 298-315.

Francesch, M. Bases de la utilización de complejos enzimáticos en avicultura. In: Curso de Especialización Avances en Nutrición y Alimentación animal, Madrid. Anais... Madrid: FEDNA, 1996. 118-131. 
Giraldo, L.A.; Tejidoa, M.L.; Ranillaa, M.J.; Carro, M.D. Effects of exogenous fibrolytic enzymes on in vitro ruminal fermentation of substrates with different forage: concentrate ratio. Animal Feed Science and Technology, 2008, 141, 306-325.

Gupta, R.; Gigras, P.; Mohapatra, H.; Goswami, V.K.; Chauhan, B. Microbial a-Amylases: Biotechnological Perpective, Process Biochemistry, 2003, 38, 15991616.

Harger, C.; Sprada, D.; Hiratsuka, E. Amilase fúngica In: Bioquímica das fermentações, 1982. 56 p.

Kameda, E.; Queiroz Neto, J.C.; Langone, M.A.P.; Coelho, M.A. Removal of polymeric filter cake in petroleum wells: A study of commercial amylase stability. Journal of Petroleum Science \& Engineering, 2007, 59, 263-270.

Medeiros, S.R.; Lanna, D.D.P. Uso de aditivos na bovinocultura de corte. In: Simpósio Goiano Sobre Produção De Bovinos De Corte, 1999, Goiânia. Anais... Goiânia: Colégio Brasileiro de Nutrição Animal, 1999, 171-190.

Miller, G.L. Use of dinitosalicylic acid reagent for the determination of reducing sugar. Analytical Chemistry, 1959, 31, 3, 426-428.
Minafra, C.S. Produção e Suplementação com a-amilase de Criptococcus Flavus e Aspergillus niger HM2003 na Dieta de Frangos de Corte de um a 21 dias de idade. 2007. p.141, Tese (Doutorado em Bioquímica Agrícola) - Universidade Federal de Viçosa, Viçosa.

Pandey, A. et al. Enzyme Technology. $1^{\text {a }}$ ed. New Delhi: Asiatech Publishers, 2005. 760 p.

Passini, R.; Rodrigues, P.H.M.; Castro, A.L.; Silveira, A.C. Parâmetros de fermentação ruminal em bovinos alimentados com grãos de milho ou sorgo de alta umidade ensilados. Revista Brasileira de Zootecnia, 2003, 32, 5, 1266-1274.

Tricarico, J.M.; Johnston, J.D.; Dawson, K. Dietary supplementation of ruminant diets with an Aspergillus oryzae a-amylase. Animal Feed Science and Technology, 2008, 145, 136-150.

Tilley, J.M.A.; Terry, R.A. A two stage technique for the in vitro digestion of forage crops. J Br Grassl Soc., 1963, 18, 104-111.

Yang, X.; Chen, H. Gao, H.; Li, Z. Bioconversion of corn straw by coupling ensiling and solid-state fermentation. Bioresource Technology, 2001, 78, 3, 277-280. 